\title{
The Application of Multiple Intelligences Theory in Mathematics Teaching
}

\author{
Nan WANG ${ }^{1, a}$ \\ ${ }^{1}$ Fundamental Education College, Beijing Polytechnic \\ Beijing, China \\ a85454456@qq.com
}

\begin{abstract}
The construction of high-end technical and skilled personnel training project in Beijing is not only the need of social development, but also the need of school education development. Through the application of multiple intelligences theory in mathematics class, teachers can correctly treat the diversity of intelligences, comprehensively and accurately understand the distribution of students' intelligences, objectively and fairly evaluate students, adopt the strategy of teaching students according to their abilities, so that students can achieve the best learning effect and maximize the development of their potential.
\end{abstract}

Keywords-Multiple intelligences; Mathematics teaching; Application; Theory

\section{INTRODUCTION}

Traditional intelligence theory holds that linguistic ability and mathematical logic ability are the core of intelligence, and intelligence is a kind of ability existing in the way of integration of the two. In view of this traditional narrow definition of intelligence, which only lingers at the operational level, but does not reveal the whole picture and essence of intelligence. In the 1980s, Gardner, a cognitive psychologist at Harvard University, put forward the theory of multiple intelligences, which defines intelligence as the ability of human beings to solve problems and create in specific situations. $\mathrm{He}$ believes that each of us has eight main intelligences: linguistic intelligence, logical-mathematical intelligence, spatial intelligence, sports intelligence, music intelligence, interpersonal intelligence, introspective intelligence and natural observation intelligence.

He put forward the concept of "intelligence-based evaluation" and expanded the basis of student learning assessment. He advocated "situational" assessment and corrected the functions and methods of previous education assessment. Pluralistic theory points out that human beings have eight kinds of intelligence and are combinatorial. The theory of multiple intelligences emphasizes the multidimensional, difference and practicality of human intelligence, promotes the development of quality education, and makes every student's intelligence develop and optimize to a certain extent.

\section{APPLICATION OF MULTIPLE INTELLIGENCES THEORY}

Education is a process of interaction between teachers and students. Only when teachers understand the characteristics and ideas of students can they work with a definite aim. The students who have just entered the through training class do not have the pressure to go to school, and they themselves do not feel the pressure of employment. They are very tired and have no goals in their study.

As a teacher of cultural basic courses, if he lacks an accurate and comprehensive macro-understanding and grasp of all the students, does not know what the students are thinking and what they want to do, it will lead to the lack of direction and pertinence in some education and teaching work, and the work effect is not outstanding. Based on this situation, we try to integrate the theory of multiple intelligences into mathematics classroom teaching, and get some enlightenment for education and teaching.

\section{USING QUESTIONNAIRES TO UNDERSTAND STUDENTS}

Knowledge of preparatory knowledge. To study a function, we mainly study its properties, such as definition domain, range, parity, monotonicity and so on. A good tool to study these properties is function image. Students have learned about the image and properties of primary function, inverse proportional function, quadratic function, logarithmic function and exponential function, and have a good understanding of the idea of combination of logarithm and shape. Learning the image and properties of trigonometric functions already has the mathematical method and thought of research.

The situation of students themselves includes the following aspects (in the form of questionnaires): students' interests and hobbies; what aspects and abilities of students do they possess? what kind of knowledge do students want to know? suggestions for mathematics.

Questionnaire design: consider the design topics from the perspective of students' multiple intelligence development, and strive to be close to students. The questionnaire designs the topic from 8 aspects of intelligence, striving to be concise, so as to avoid students' boredom. 6 or 9 options for each topic to facilitate final statistical results. Students whose options cannot include students' ideas can be specified. the anonymous 
questionnaire is used to get the most authentic idea of the students.

Survey shows: The subjects of this survey are students of four professional development directions in grade one. A total of 136 questionnaires were sent out and 133 valid questionnaires were collected, with an effective rate of $97.79 \%$.Students are very active in doing this questionnaire, one may be fresh curiosity; the other may be that students can use this questionnaire to express their feelings.

TABLE I MULTIPLE INTELLIGENCE QUESTIONNAIRE AND STATISTICS (THE TABLE SHOWS THE TREND OF STUDENTS' ABILITIES IN DIFFERENT MAJORS, AND THE STATISTICAL RESULTS ARE EXPLAINED BY PERCENTAGE).

\begin{tabular}{|c|c|c|c|c|c|c|c|c|}
\hline $\begin{array}{c}\text { multiple } \\
\text { intelligence } \\
\text { major }\end{array}$ & Language & $\begin{array}{l}\text { Math } \\
\text { logic }\end{array}$ & $\begin{array}{l}\text { Visual } \\
\text { spatial }\end{array}$ & $\begin{array}{c}\text { Body } \\
\text { movement }\end{array}$ & $\begin{array}{l}\text { Music } \\
\text { melody }\end{array}$ & $\begin{array}{c}\text { Inter- } \\
\text { personal }\end{array}$ & $\begin{array}{c}\text { Self- } \\
\text { cognition }\end{array}$ & $\begin{array}{l}\text { Natural } \\
\text { observer }\end{array}$ \\
\hline Arts and crafts design & $36.6 \%$ & $41.3 \%$ & $40 \%$ & $57.3 \%$ & $64 \%$ & $78 \%$ & $67.3 \%$ & $37.3 \%$ \\
\hline $\begin{array}{c}\text { Automobile } \\
\text { manufacturing }\end{array}$ & $32.4 \%$ & $46.4 \%$ & $47.8 \%$ & $56.1 \%$ & $56.5 \%$ & $60.5 \%$ & $59.5 \%$ & $39 \%$ \\
\hline $\begin{array}{c}\text { Information } \\
\text { technology specialty }\end{array}$ & $39.3 \%$ & $42.5 \%$ & $42.9 \%$ & $56.8 \%$ & $65.6 \%$ & $58.1 \%$ & $52.2 \%$ & $43.1 \%$ \\
\hline Business management & $36.8 \%$ & $41.9 \%$ & $53.5 \%$ & $58.5 \%$ & $60.1 \%$ & $78.7 \%$ & $60.1 \%$ & $42.9 \%$ \\
\hline
\end{tabular}

The questionnaire shows the development of multiple intelligences among students of different specialties. The proportion of the development of interpersonal intelligence in the eight functions of the four majors is $78 \%, 60.5 \%, 58.1 \%$ and $78.7 \%$ respectively, ranking first. Secondly, the students majoring in Arts and crafts design develop better in selfcognitive intelligence, music melody intelligence and body movement intelligence; the students majoring in automobile manufacturing develop better in self-cognitive intelligence and body movement intelligence; the students majoring in information technology develop better in music melody intelligence; and the students majoring in enterprise management develop better in music melody intelligence. Self -cognitive intelligence and music melody intelligence develop better. The language intelligence and natural observer intelligence of the four major students are poor, and their mathematical logic intelligence and visual space intelligence are also poor, which indicates that the development of students' multiple intelligences is unstable.

\section{TEACHING CASE: USING MULTIPLE INTELLIGENCES TO TEACH THE IMAGE AND PROPERTIES OF SINE FUNCTION}

Natural intelligence: Taking the cycle of spring, summer, autumn and winter, clocks and clocks, minute hand and second hand revolving around and around as an example, the concept of periodicity is introduced, so that students can develop their natural intelligence by tapping natural phenomena.

Self -cognitive intelligence: The students discover the natural law by finding the natural phenomena. Let the students reflect on these rules in the past life often contact, but did not intentionally summarize their links. On the basis of the known periodicity of natural phenomena, students study whether the functions in mathematics also have such periodicity. Take sine function as an example, study its periodicity, and develop Self cognitive intelligence and self-reflection intelligence.
Speech language intelligence. After analyzing and studying the periodic change of sinusoidal function, let students sum up these rules in language, and inspire students to try to summarize the definition of periodic function and develop speech-language intelligence.

Body kinesthetic intelligence. By drawing sinusoidal function images by hand, practical ability is improved and their Body-kinesthetic intelligence is developed.

Vision space intelligence. By observing the image of sinusoidal function in a period and combining the image of sinusoidal function in the whole definition domain, the spatial imagination ability is improved. According to the observation image, we get the nature of sine function and develop students' visual spatial intelligence.

Music rhythm intelligence. In order to relax nerves, regulate classroom atmosphere and improve their learning efficiency, students can play slow-paced music during class practice time, avoid the negative effects of using strong sense of rhythm or popular songs to distract students' attention, and develop music-rhythm intelligence.

Logic mathematical intelligence. After learning the images and properties of sinusoidal function, let students consolidate their mastery of knowledge points through exercises, deepen their understanding and application of knowledge, such as using the monotony of sinusoidal function to compare the value of trigonometric function, so that students can develop their logical-mathematical intelligence by using the knowledge they have learned.

Interpersonal intelligence. After class exercises are grouped in groups and asked by group questions. Improve teamwork ability, cultivate students' sense of unity and cooperation, and develop communicative-communicative intelligence. 


\section{TEACHER ANALYSIS AND DISCUSSION}

Students' mastery of knowledge; The improvement of ability is analyzed and compared by using the theory of multiple intelligences. Find out the existing problems and make suggestions for improvement. Conduct comparative analysis among different professions.

Students of different majors and abilities are suitable for different theories of multiple intelligences, reflecting the role of multiple intelligences theory. To apply the theory of multiple intelligences widely in mathematics classroom, we need to face more students, more units, more semesters to explore and formulate more detailed and effective implementation plans and plans, seriously summarize the experience and lessons in the implementation process, continue to explore and research, and better use of multiple. Intelligence explores the full potential of students.

There is a great gap between understanding and mastery of knowledge, which is bound to have a negative impact on mathematics teaching. Under such circumstances, most of our mathematics teachers still adopt the traditional teaching method of "one size fits all", which leads to the widening of the difference. In this way, we must not face all the students and take full account of their individual differences, which is not conducive to the full development of potential. Therefore, we should not avoid such differences in teaching.

\section{SUMMARY}

The theory of multiple intelligences tells us that a single individual has a high degree of intelligence, but not necessarily the same level of other intelligence. Only when students' individual differences are taken into consideration can teaching be effective.

For those students who have spare energy and strong interest in mathematics, teachers can provide them with enough learning materials to meet their learning needs and promote the further development of mathematical intelligence. In addition, teachers should organize more students or discuss and communicate with teachers. In terms of the content of communication, we can discuss the understanding of mathematical concepts and properties, and also debate the design and solution of some mathematical problems.

In addition, in mathematics teaching, teachers should respect the individual characteristics of each student, allow different students to understand problems from different knowledge perspectives, and express their ideas in different ways. Teachers should encourage students to solve the diversity of problem strategies and make different students develop differently.

The development of students' intelligence through training is more individual than that through training. Mathematics teaching should not only fully develop each student's superior intelligence, but also pay attention to the excavation and compensation of students' individual weak intelligence, so that students' multiple intelligences can be developed in an allround way, reflecting the promotion of students' comprehensive, continuous and harmonious development in mathematics curriculum. The curriculum objectives of the exhibition.

The theory of multiple intelligences, with its unique interpretation of intelligence and great integration, provides a theoretical basis for the professional development of mathematics teachers. Especially in renewing teachers' traditional educational ideas and enriching their teaching practice, it opens up a new horizon. The theory of multiple intelligences can prompt teachers to rethink the current problems of mathematics education and teaching from a new perspective, and provide new ideas and ideas for the improvement of teaching and evaluation views.

Teachers can create a relaxed and harmonious learning environment for students and provide a space for the development of multiple intelligences. Let students have the opportunity to fully express themselves, enhance their selfconfidence and develop their potentials. Under the influence of multi-education concept, "everyone has talent, no one has allround talent, develop strengths and avoid weaknesses, everyone becomes a talent" education concept will eventually become a reality.

\section{REFERENCES}

[1] Reconstructing multiple intelligences [M]. Renmin University of China press, (USA) Gardiner, 2008.

[2] Enlightenment of Multiple Intelligence Theory on Innovation of Higher Vocational Education [J]. Journal of Jiangsha Nanchang Institute of Education, Su Yelan, 2009 (02).

[3] Enlightenment of Multiple Intelligence Theory on Vocational Education [J].Yang Jinmei. Journal of Tianjin Vocational and Technical Teachers College.2003(02).

[4] Using multiple intelligences theory to guide teaching practice in vocational schools [J]. Luo Huifen. Vocational Education Forum. 2003 (18).

[5] Social Etiquette Course Teaching in Higher Vocational Colleges Guided by Multiple Intelligence Theory [J]. Liu Lei. Social Science Vertical and Horizontal (New Theory Edition). 2011 (03).

[6] Heory and Practice of Multiple Intelligences: Let every child develop on the basis of his own strengths [Building on Giiildres's Strengths: The Experience of Project Spectrum] [M]Chen Jieqi, [US] Howard Gardner, David Henry et al. Translated by Fang Junjun, Li Jimei, Liu Xiaoyan. Publishing House of Beijing Normal University.2015.6.

[7] "Teaching well" student needs a process [J]. Yushan Pan. Jiangsu education. 2017 (04).

[8] On the theory of multiple intelligences and accounting teaching in Vocational Education [J]. Zhang Weifen. Occupation. 2017 (34).

[9] Dilemma and Countermeasure of Talents Training in Higher Vocational Colleges: From the Perspective of Multiple Intelligence Theory [J]. Xue Shan. Journal of Tianjin Sino-German University of Applied Technology. 2018 (01).

[10] Research on curriculum design of Higher Vocational Education Based on multiple intelligence theory [J]. Sun Zhen. China National Expo. 2018 (02). 